Bol. Acad. peru. leng. 47. 2009 (149-168)

\title{
CUENTOS DE BOLSILLO DE HARRY BELEVAN O DOBLE TRAVESÍA DE LA ESCRITURA FANTÁSTICA
}

\author{
Manuel Pantigoso \\ Academia Peruana de la Lengua
}

Teniendo como base de estudio el último libro de relatos de Harry Belevan titulado Cuentos de bolsillo -que aluden a lo oculto, a aquello que al ser extraído se revela con todo su sarcasmo o su perspicacia imprevista-, el presente ensayo rastrea las múltiples posibilidades de la expresión fantástica y de sus ramificaciones que se inician en los primeros años del siglo $\mathrm{XX}$ y tienen creciente vigencia en la actualidad. Luego de explicar de qué manera el autor se desentiende del referente real inmediato para centrar su interés en la literatura como realidad en sí misma, el trabajo sostiene que lo fantástico está en el centro mismo de lo expresivo y representativo del texto; es decir, cumple una función meta-literaria. Los ejemplos colocados permiten revelar que frente a una descripción aparentemente simple, o a un hecho cotidiano, el texto se ilumina de pronto gracias a su raíz polisémica y sutileza verbal, teniendo como elementos potenciales a las paradojas, los juegos a contraluz, la gracia y la ironía bien calculadas, etc. Finalmente, los relatos de Belevan son vistos, por su esencia vanguardista y moderna, desde la perspectiva de la narrativa contemporánea en cuanto sus rasgos más relevantes: descenso al yo, ilogicidad, descubrimiento del otro, tiempo interior, subconsciente, incomunicación.

"El mundo fantástico no está afuera, o arriba, o abajo; está en el fondo de nosotros, lo mueve todo, es el alma de toda realidad"

George Sand, Ensayo sobre el drama fantástico. 
"La imagen moderna o visionaria no es el resultado de una aberración. Es un producto tan específicamente humano, que el alma de todos los hombres lo elaborará desde siempre en el sueño, en el proceso onírico".

"Cuanto mayor sea (dentro de ciertos límites) la distancia entre la realidad y la evocación, más grotesco será el resultado”.

Carlos Bousoño, Teoría de la expresión poética

\section{Inicio de la travesía fantástica}

En los años sesenta y setenta del siglo pasado, cuando un nuevo orden social obliga al escritor a revisar su concepción del mundo y a replantear su relación con la sociedad, se produce en algunos narradores peruanos un desvío del foco de atención desde los problemas sociales y colectivos hacia los más íntimos, allí donde la subjetividad del ser humano esplende. En las publicaciones tardías de algunos integrantes más o menos marginales de la generación del cincuenta se produce también un distanciamiento del neorrealismo para acercarse, más bien, al cultivo del cuento fantástico. Dentro de ellos están Felipe Buendía, Cuentos de laboratorio (1976); Juan Rivera Saavedra, Cuentos Sociales y de ciencia-ficción (1976); José B. Adolf, Invisible para las fieras (1972), Cuentos del relojero abominable (1974), Mañana fuimos felices (1975); Luis Loayza, El avaro y otros textos (1974).

Aunque los cuentos de modalidad fantástica no constituyen una novedad en la literatura peruana, pues ellos están presentes en los primeros años del siglo XX con Clemente Palma y se desarrollan de manera desigual en otros autores especialmente en algunos de la generación del 50, Harry Belevan se empeñó en impulsar la expresión fantástica no solo mediante sus cuentos sino, también, mediante la publicación de una Teoría de lo fantástico (1976) y, sobre todo, una Antología del cuento fantástico peruano 
(1977), ${ }^{1}$ donde sostenía -frente a la coincidencia de la crítica en señalar la inexistencia de una tradición fantástica peruana- que existe desde antiguo una narrativa fantástica con raíces perfectamente definibles, y trataba de demostrarlo con la selección de cuentos que presentaba.

\section{La visión y la pasión del personaje}

Harry Belevan nació en Lima en 1945. Ha ejercido la docencia en distintas universidades del Perú y del extranjero. También colabora regularmente en diversos medios con temas literarios y de política internacional. Ha publicado -además de los dos textos citados- los libros de cuentos: Escuchando tras la puerta (1975) y Fuegos artificiales (1986); el ensayo Cambio y continuidad (1996); y la novela La piedra en el agua (1977). Además, es autor del libro de crónicas: Pruebas al canto, y de varias piezas teatrales.

Uno de los rasgos esenciales de su narrativa es la extraterritorialidad en que se ubica su mundo creativo. Debido a la vida nómada por ser hijo de diplomáticos y diplomático él mismo, ${ }^{2}$ su formación cultural y su fuente de inspiración se arraigan en la misma literatura, su único bagaje universal y perenne que se enfrenta a esa otra vida marcada por los continuos desplazamientos. Su ficción arrancará, así, de otras ficciones, "situándose al otro lado del otro lado de la realidad", como lo ha señalado.

1 Los relatos incluidos son: Los ojos de Lima, La Granja Blanca, La leyenda de Hachisch de Clemente Palma; Una posesión judicial de Enrique López Albújar; La momia, La llama blanca de Ventura García Calderón; Los ojos de Judas, Finis Desolatrix Veritae de Abraham Valdelomar; Más allá de la vida y la muerte, Teoría de la reputación de César Vallejo; El pájaro dorado o la mujer que vivía bajo el árbol del pan de Carlota Carvallo de Núñez; La apoteosis de la maestra de María Tellería Solari; El baúl de Felipe Buendía; Doblaje, Ridder y el pisapapeles de Julio Ramón Ribeyro; Marita en el parque de José B. Adolph; Muerte y resurrección de Santiago el viejo de Eduardo González Viaña; Que en paz descanse Antonio B., Maimónides el filósofo de Harry Belevan. En 1940, Jorge Luis Borges y Adolfo Bioy Casares publicaron Antología de la literatura fantástica. En el Perú, Felipe Buendía editó: Literatura Fantástica, en 1959.

2 Actualmente se desempeña como Embajador del Perú en Francia y como Delegado Permanente ante la UNESCO.

Bol. Acad. peru. leng. 47(47), 2009 
La salida liberadora de ese parametraje profesional que es la diplomacia - donde reina lo formal, la impostación, el cuidado de los asuntos tratados- es una especie de respuesta complaciente para llegar a aquella extraterritorialidad en donde no hay límites para la exacerbación del pensamiento y del espíritu. Por ello, Belevan dirá en su libro Pruebas al canto:

"Los verdaderos diplomáticos (esos que ya prácticamente no existen) son como los cisnes: navegan deslizándose por el mundo, todo souplesse, todo aisande (dicho inexorablemente en francés), serenos, relentes, ecuánimes, ponderados, siempre compuestos. ¡Pero nadie observa cómo pedalean debajo de las aguas!”.

"Mi vida ha sido nómada. Mi memoria, sedentaria. Escribir ha sido siempre un intento por revertirlas".

\section{La visión calidoscópica del autor y sus maestros}

Con Cuentos de bolsillo, Lima, Editorial Universitaria, 2007, publicado por la Universidad Ricardo Palma, Harry Belevan afianza en el Perú una narrativa de inflexión fantástica que, premeditadamente en su caso, se desentiende del referente real inmediato para centrar su interés, como hemos dicho, en la literatura como una realidad en sí misma. El libro quiere plantear otro concepto del cuento y de la literatura, y cuestionar ciertos aspectos como aquellos relacionados con la ideología y la función de la escritura, o como la literatura en tanto realidad diferente del mundo en que vivimos.

Destaquemos -como marco teórico del impulso y de la orientación estética ligadas a lo ficcional y a lo fantástico- algunas definiciones que Belevan toma de Tzvetan Torodov, Irène Bessière, Louis Vax, Marcel Brion, Marcel Schneider y Roger Caillois. Ellas aparecen en su notable libro Teoría de lo fantástico: 
- Tzvetan Torodov:

- $\quad$ "Tanto la incredulidad total como la fe absoluta nos llevarían fuera de lo fantástico, lo que le da vida es la vacilación [...] lo fantástico implica una integración del lector con el mundo de los personajes; se define por la percepción ambigua que el propio lector tiene de los acontecimientos relatados" (41).

- "La vacilación del lector es pues la primera condición de lo fantástico" (45).

- "Lo fantástico es un caso particular de la visión ambigua" (45).

- Irène Bessière:

- $\quad$ "El relato fantástico tiene como particularidad la de denunciar la disparidad de lo real para dibujar un orden superior solo mediante la letra" (58).

- Louis Vax:

- "Lo fantástico se nutre del escándalo de la razón" (62).

- $\quad$ "El momento de lo fantástico es aquel en que la imaginación está empeñada ocupándose de mirar lo real, en pedirlo. Entonces tenemos la impresión de una subversión, de una parodia monstruosa" (64).

- Marcel Brion:

- "La imaginación del hombre sugiere una presencia imperceptible, indiscernible, cuyos prodigios no pueden ser, entonces, ni definidos ni representados" (67).

- Marcel Schneider:

- "Lo que buscamos en lo fantástico no es una evasión, un pretexto, menos aún una venganza; buscamos un secreto que es a la vez secreto del hombre con el universo" (71).

- Roger Caillois:

- "Lo fantástico supone la solidez del mundo real, pero para asolarlo” (76). 
Estas "llaves" que nos han de permitir ingresar con mayor solvencia en el libro de Harry Belevan. Es evidente que la razón de ser de la ficción en los micro relatos que forman los Cuentos de bolsillo no es representar lo real en tanto existencia verdadera y efectiva, sino negar lo real y trasmutarlo en una realidad que parezca más real que la misma realidad. Inclusive, lo que puede resultar secundario, adjetivo o circunstancial alcanza, gracias a la intensificación expresiva, un alto grado de plenitud, de evocación insospechada que cautiva y maravilla. El siguiente trozo de "La corbata de Descartes" puede resultar significativo:

"Sin embargo y por más que se lo propuso, no pudo el gran filósofo pensar en otra cosa que no fuese su corbata roja y verde durante esos minutos -ique se hicieron eternos!- que tomó el aterrizaje de emergencia. Por eso, cuando el avión se detuvo y los pasajeros lograron sobreponerse al tremendo susto, se juró que, fuere lo que fuere y se pensara de él lo que se quisiera, jamás volvería a viajar sin colgarse al cuello su corbata roja y verde".

(“La corbata de Descartes", 23-24).

\section{Los campos magnéticos: fantasía y metalenguaje}

Harry Belevan usa la imaginación y la ficción para impulsar el encuentro de respuestas menos convencionales. Lo fantástico está en el centro mismo de lo expresivo y representativo del texto, rebasando el ámbito de lo humano para adquirir mayores valores, o para intensificarlos. Dichos textos contienen, pues, una función meta-literaria.

La naturaleza de lo fantástico aparecerá, así, en el manejo del lenguaje, en el brillo de sus propias resonancias y sortilegios, pero esta narrativa tiende por lo general a retardar el desenlace de las acciones; el autor siempre retrasa el suspenso, así alarga lo fantástico entre los recovecos del lenguaje para expresar el desconcierto, la expectativa, o, sencillamente, para darle una mayor dimensión a lo narrado. En el siguiente ejemplo se evidencia este procedimiento, donde el personaje central dialoga con la muerte: 
"Aunque nadie nunca había podido atestiguar antes de lo que se siente en ese rescoldo terminal de la cariocinesis que se denomina la telofase -el sarrillo o estertor del moribundo para decirlo en lenguaje del vulgo- él sí lo logró aprovechando ese centésimo quincuagésimo millonésimo de segundo cuando, allí de pie frente a su lecho, esquelética y apoyada en su guadaña, Ella se tomó un respiro - es un decir- antes de proceder".

(“El funeral”, 63).

En el párrafo notamos que abundan las palabras aparentemente vacías de contenido: aunque, nadie, nunca, había, antes de lo que se. El verbo -el que señala la acción- está estancado ("podido atestiguar") o casi llega al final ("se siente"). En el texto hay un deseo de retardar la muerte. Por lo menos hemos contabilizado 29 relatos de los 67 que componen el libro, en donde la muerte es el leit motiv principal: Que en paz descanse Antonio B...; El adivino, el ladrón y el asesino; La viuda del General; La importancia de las letras; El suicida; El aprendiz de adivino; La inmortalidad; Lo que la Venerada Emperatriz...; Jugando a las escondidas; Otra versión de la muerte; Foto velada; El jefe no siempre tiene la razón; El fallo; El analfabeto; La verdad y las mentiras; Estado de derecho; El funeral; Refranero popular; Murió en su ley; La última parábola; ¿Meras coincidencias?; Siete añitos para nueve; El retrato de Dora Gris; Puntualmente; Pie de página; siempre a sus gratas órdenes; La azarosa pero desopilante historia de doña Severina (I); La azarosa pero desopilante historia de doña Severina (II); Macabra ironía. ¿El retardo lingüístico que hemos captado no estaría revelando el deseo de evadirse de la muerte inexorable? En "Otra versión de la muerte" (37) leemos al final de la narración:

"Cuando el esclavo hubo partido el amo se dirigió resueltamente a Bagdad en busca de la siniestra deidad, la encontró y le espetó: ‘Cómo te atreves a amedrentar a mi fámulo y por qué lo has hecho?. Pero ella se disculpó: 'Yo no le he espantado ni era mi intención hacerlo. Por el contrario, me sorprendí yo misma y eso debió seguramente reflejarse en mi rostro, nada más. Me asombró apenas encontrarlo en Bagdad porque más tarde tengo una cita con él en Asmara. Y no sé cómo hará para llegar a tiempo". 


\section{Reverso y anverso de las palabras}

Los textos tienen en esencia raíz polisémica, que permite revelar sus escondidas posibilidades expresivas en el aspecto semántico, como se observa con toda su potencia irónica en "Acerca de la susceptibilidad" (92), en donde una pareja de esposos entran a una zapatería para preguntar el precio de los calzados. Ella tiene una limitación: es coja desde la infancia; él es un tipo excéntrico, apodado por eso "el loco":

"El vendedor de la dentífrica sonrisa le respondió

- ¡Escoja!”

El marido se irritó con la tremenda impertinencia, aunque la dejó pasar. Pero cuando él decidió comprarse también unos zapatos y el mismo insolente mozalbete le dijo "lo coloco" refiriéndose naturalmente a si debía empacar el nuevo calzado o si se lo llevaba puesto, el hombrecillo no pudo contenerse y arremetió con santa ira contra el desvergonzado vendedor por los inaceptables agravios de los que su esposa y él acababan de ser objeto".

De factura similar respecto a la potencia corrosiva de las palabras en contextos individuales, es el titulado "Por la amada patria" (61) en donde el sentido es doble por ser "nada" una parónima:

"La profesora le preguntó al alumno disipado: -iQué hace el pez en el agua?

-Nada - fue la respuesta contundente.

Muy enojada, la profesora expulsó nuevamente de la clase al alumno disipado, y esta vez por atrevido.

Por cierto que el zagal no entendió el motivo del castigo pues bien sabía que el pez en el agua nada. Pero, igual, aceptó una vez más la sanción aunque juró que algún día se vindicaría de todas las injusticias sufridas en el colegio".

Como éstos, otros relatos tienen varios niveles de lectura. Frente a una descripción aparentemente simple de un hecho cotidiano o anodino el texto se ilumina de repente a través de una "finta" o sutileza verbal. Para 
ello se requiere de un lector avisado y "avezado", perspicaz y atento, que adivine o descifre aquellas reconditeces que, puestas ante una luz cenital, se agrandan o se potencian gracias a la polisemia y al ludismo verbal. La esencia de lo fantástico está, pues, en invitar al lector a descubrir aquello que se oculta y se guarece detrás de las palabras. El hecho maravilloso será atrapado al otro lado del espejo, en su reverso, en su oscuro margen. El lector (que es también autor porque forma parte del proceso creativo) va explorando cada una de las "capas" del lenguaje, va paladeando lentamente sus escondrijos mientras encuentra nuevas correspondencias y asociaciones lingüísticas, nuevas resonancias inverosímiles que desde la óptica del narrador resultan reales.

\section{Las visiones en la comicidad}

Las paradojas, los juegos a contraluz, el reverso y el anverso de la palabra, la gracia y la ironía bien calculadas, son los principales resortes del lenguaje de Harry Belevan. Uno de los sustentos fundamentales de su narrativa es también el humor. Desde Aristóteles, una gran cantidad de filósofos y pensadores han tratado de desentrañar el funcionamiento del humor y de saber aquello que produce ese súbito estallido. Dos libros importantes del siglo XX son La risa (1900), de Bergson, y El chiste y su relación con el subconsciente (1905), de Sigmund Freud. Por su lado, Schopenhauer escribió sobre la risa en El mundo como voluntad y representación (1819):

"Cuando más legítima es en un respecto la subsunción de tales realidades bajo el concepto, y cuanto mayor y más detonante por otro su incongruencia con él, tanto más fuerte es el efecto cómico que nace desde esta oposición".

Esta iluminadora explicación sobre el mecanismo humorístico se asemeja sorprendentemente a la estructura poética de la poesía vanguardista: una calculada yuxtaposición de opuestos. Y más específicamente, con la sucinta formulación de Reverdy que inicia la aventura cubista, ultraísta, o surrealista diciendo -en relación a la imagen poética- que mientras más lejanas y justas sean las relaciones de las dos realidades aproximadas, más 
fuerte será la imagen, es decir, tendrá mayor potencia emotiva y realidad poética. Siguiendo este postulado, los "relatos de bolsillo" tienen, sin duda, factura vanguardista precisamente por esas "relaciones lejanas y justas".

En la obra de Belevan encontramos los mismos mecanismos de impacto cuando desarrolla la experiencia humorística a través de sus personajes. Aunque allí las relaciones no son "distantes" o "incongruentes" en sí mismas sino que el contexto es el que produce esas direcciones diferentes que, a la postre, desencadenan la risa:

"A las ocho y cuarenta y cuatro minutos de la noche -bien lo recuerda ella pues, sollozando, atinó a mirar el despertador porque sintió en su corazón que ese habría de ser el último suspirofalleció el día $\mathrm{N}$ del año X el señor Juan de Dios Llanos.

La viuda se negó a contar hasta a sus propios hijos la dolorosa anécdota (por extraña y, en verdad, casi cómica que fue), y solo después de mucho tiempo les confesó en susurros: 'Estaba recostado en su cama -les dijo-, durmiendo tranquilito y hasta roncando, cuando de pronto saltó como un resorte y gritó: 'Han suprimido la elle, la elle, la elle se acabó! ¡Cabrones, me han asesinado! Fue todo lo que dijo y allí mismo nomás se desplomó”.

(“La importancia de las letras", 22).

Aquí se aprecia cómo un edicto de la Real Academia Española de la Lengua, que decidió eliminar del diccionario la letra "Ll", puede cegar la vida de un individuo cuyo apellido paterno empieza precisamente con esa letra extinta (Llanos). Frente a la "gravedad" de esta humorada, el texto aporta múltiples intenciones: la de los académicos (los "inmortales" que matan, joh ironía!), la de los personajes (que pasarán a llamarse Juan de Dios Lanos o Juan Lanos y otro será Lona en lugar de Llona), la del propio autor (el narrador que cuenta) e, inclusive, la del lector (que pensará en otros nombres que sufrirán el mismo menoscabo). El narrador confronta sus personajes con las más diversas experiencias y acciones. Ellos son protagonistas (sin conciencia plena) que realizan el propósito del autor: crear un mundo literario que apunte hacia lo humano. 


\section{Ruptura del sistema lógico}

Con poderosa imaginación Belevan carga su narrativa de soluciones imprevistas. La misma imaginación es arropada con mayor fantasía. Esto es el non plus ultra, la irracionalidad de lo fantástico que, sin embargo, no puede entenderse - como hemos dicho- sino a partir de la misma realidad. En último caso, lo fantástico es la propia realidad, que es más fantástica que ella misma. Veamos este fragmento del cuento "Los círculos concéntricos" (31):

"La entrevistadora llegaba al final de su reportaje y sintió que debía hacerle las últimas preguntas de rigor a la afamada autora que estaba entrevistando:

- ¿y qué está haciendo ahora?

- Hablando con usted

- No. Me refiero a qué cosa está escribiendo ahora.

- Un cuento

- ¿Y cómo se llama?

- "La entrevistadora"

- ¿Y de qué se trata?

- De una entrevistadora que le pregunta a una afamada autora que qué está haciendo ahora”.

En suma, esta literatura está destinada a ofrecer metáforas de la realidad por medio de las cuales el escritor no se evade de ella para ingresar en un territorio impune sino utiliza el mismo lenguaje y su azaroso despliegue de significantes y significados. Recordemos El hombre invisible de H. G. Wells y El proceso de Franz Kafka. Ambas obras plantean el mismo tema: la soledad del hombre, su incomunicabilidad última, pero utilizando distintos procedimientos narrativos. La obra de Wells - precursor de la ciencia-ficciónes una fantasía científica, contada en términos de minucioso realismo; la obra de Kafka, por su lado, es una pesadilla que conserva su irrealidad, su angustia, pese a estar expuesta con detalles de la más penosa o trivial materialidad.

En el centro de las ficciones de Belevan hay una intención que no es difícil percibir: este mundo que creemos vivir gobernado por la razón y 
fijado en inmutables categorías morales e intelectuales es, en verdad, una invención de los hombres que se superpone a la misma realidad absurda y caótica. En el cuento "En la ciudad de las piedras" (28) leemos esta mezcla de ironía, representación del absurdo y defensa de lo humano:

"Todo parecía equivocado desde siempre en la ciudad de las piedras. Hasta el nombre de las cosas: había una peluquería de damas que se llamaba Coiffure le Dragon d'or al lado de un restorán de comida china llamado La bella Parisién. Pero todo se arregló para siempre cuando el organillero demostró, con pruebas al canto, que él era de carne y hueso y no de piedra”.

\section{El alma en la caverna: los rastros de la escritura}

La naturaleza física y visual de estos cuentos alude, como ya se ha dicho, a lo oculto, a lo guardado, a aquello que al ser extraído y mostrado se revela con todo su sarcasmo, ironía o perspicacia imprevista. Visto de este modo, el narrador será como un mago o un prestidigitador que extrae sorpresas de su bolsillo. El humor no puede faltar en ellos. Lo confirma, entre otros, el cuento "Homenaje a E" (45) en donde el autor se describe durante el desdoblamiento, el autoconocimiento e inclusive el temor y la autodestrucción en el acto de la escritura:

"La crítica especializada así como sus millones de lectores eran unánimes: se trataba del más destacado cultor de cuentos ínfimos de todos los tiempos. Por eso se sorprendió cuando, al terminar de corregir el más reciente de sus brevísimos relatos, sintió que había llegado la hora de escribir una novela o, cuando menos, algo de mayor aliento que aquello por lo que era tan reconocido.

Se propuso, entonces, relatar las tribulaciones de un destacado autor de cuentos de bolsillo enfrentando las vicisitudes de una segunda página. Y comenzó a escribir: 'La crítica especializada así como sus millones de lectores eran unánimes: se trataba del más destacado cultor...”. 
Pero allí nomás dejó de escribir y garabateó más bien unas manos dibujándose a sí mismas, lo que le impidió para siempre seguir escribiendo".

"Las huellas del caminante" (79) nos parece un texto altamente revelador; en él Harry Belevan define, a través de "pisadas" o rastros, el símbolo no solo de su escritura sino de la literatura en general:

"La marea alta debió borrar sus huellas en la playa rumbo a la caverna rocosa, porque solo se encontraron estampadas en la orilla húmeda las de sus pies y de las pezuñas del mastín, pero camino de regreso.

Volvió entonces de aquella gruta. Y no hay duda que fue así porque para regresar primero debió ir, como resolló con profesional aplomo el investigador a cargo del caso.

Sin embargo, el fiel animal aúlla todos los atardeceres escrutando expectante la caverna. Pero el hecho es que hasta hoy, algunos años después, no se ha vuelto a saber nada del caminante".

Aquí la caverna o la cueva aludiría a ese bolsillo al que hay que acudir, el que a su vez nos remite al texto mismo, a la literatura como pasión o construcción de la vida; lo que ingresa al texto son palabras, diálogos, paradojas, oposiciones, desenlaces, etc. Pero su verdadero poder de seducción y subversión es alcanzado cuando se regresa a la cueva y se observa que en la literatura todo ello sale transformado mediante su alto poder evocativo propio del sugerente mundo representado. Lo que queda -o permanece- es el reflejo, la trascendencia, los rastros de la escritura. Por ello una buena lectura será siempre una posibilidad de encontrar la huella psicológica, la impronta emocional que el narrador ha ido dejando en su camino como consecuencia de un regreso renacido.

Octavio Paz se refiere al ritual de las dos travesías, la interna y la externa, cuando anota: "El poeta desciende, al descender desnace. Y nace, nuevamente, fénix de sangre". Este salir de sí mismo sin dejar de ser uno mismo es una suerte de soliloquio, marcado por lo que podríamos llamar "exteriorización subjetiva". Dicho soliloquio conlleva la conversación de la 
palabra con las distintas voces interiores agrupadas en la emoción virginal. Debemos entender que aquel "descenso" (o recuerdo) se produce para encontrar esa emoción pura, y que ese "ascenso" (o renacimiento) es para traer consigo la palabra encarnada... jo encantada!

Desde esta ruta, y en sentido figurado, el narrador "embolsica" o guarda en el bolsillo muchas cosas; sus fantasías, sus resquemores, sus sueños, sus esperanzas... etc.; aquel espacio mágico en donde se pierden y confunden los objetos menudos es, en realidad, el mundo interior del narrador; de allí él sabe extraer toda la carga vital, psicológica, que empapa sus "cuentos portátiles", como gusta llamarlos. Nadie sale indemne, como en la gruta de Polifemo, de Góngora, en donde anidan esos seres arrancados de nuestra subconciencia:

"Caliginoso lecho, el seno oscuro

ser de la negra noche nos lo enseña,

infame turba de nocturnas aves,

gimiendo tristes y volando graves".

\section{La poética como expresividad del lenguaje fantástico}

La brevedad de los textos de Harry Belevan adelgaza a los personajes, les niega mayor intimidad, los vuelve héroes de una épica primitiva anterior a la novela. Y así es porque muchos de ellos se desenvuelven como estampas; son arquetipos de criaturas inermes ante lo inexorable. Cada texto es síntesis de una continua y recurrente búsqueda que suscita en nosotros ricas construcciones imaginísticas capaces de evocar los goces de la palabra sin excluir esa inquietud y ese desasosiego que moran en los riscosos senderos del conocimiento.

De allí que el aparente nihilismo, la valoración de lo metafísico o las afirmaciones en torno a la vanidad de la filosofía - expresados con sarcasmo y lucidez- son puntos de partida para la valoración de lo poético, pues éste se encuentra en las imágenes intensificadas que cada lectura suscita en el individuo. Cualquier texto de Harry Belevan se mueve en la orilla 
de una atmósfera poética. Veamos este formato de "Lecciones de historia" (25) en donde la poética de lo fantástico está en el propio paisaje:

"Las olas dejaron de reventar en la orilla. Los árboles en los cantiles se silenciaron cuando el viento dejó de hacerlos crepitar. Las aves se desplomaban como si no supieran ya volar".

\section{$[\ldots]$}

"Dejó el lápiz y el papel. Se acuclilló en la arena, los brazos cruzados, a otear el horizonte. Allá en la lejanía, un trémulo sol se desmigajaba en miles de centellas fosforescentes mientras la noche se desparramaba en jirones, coagulándose en el firmamento como mancha gredosa de sangre escurriéndose sobre la inmaculada blancura de un paño de lino".

\section{Fantasía y subversión en la narrativa contemporánea}

Una lectura múltiple de los calidoscópicos y poliédricos Cuentos de bolsillo de Harry Belevan -especie de haikus narrativos- nos permite también verlos, por su esencia vanguardista y moderna, desde la perspectiva de la narrativa contemporánea. Apuntemos los rasgos más relevantes de ella:

* Descenso al yo: a la inversa de los escritores anteriores que se proponían fundamentalmente la descripción objetiva del mundo externo, el narrador de hoy se vuelve, en un primer movimiento, hacia el "misterio primordial de su propia existencia" (subjetivismo) $\mathrm{y}$, en un segundo movimiento, hacia la "visión de la totalidad del sujeto-objeto” desde su conciencia (fenomenología):

"Cuando despertó el dinosaurio todavía estaba allí. Solo entonces recordó que ese reptil prehistórico era herbívoro".

(“El suicida”, 26).

"A lo lejos creyó escuchar unas notas de la recién estrenada Cuarta Sinfonía en B menor de Beethoven, cuando despertó sobresaltado. 
Miró en derredor y llamó a Josefa, la fiel sirvienta de la casa paterna, para pedirle su café con leche matinal. Nadie respondió y mientras se desperezaba, se asomó bostezando a la ventana. Pero en la calle, varios pisos abajo, en lugar de ver la diaria congestión de aquellos microbuses que lo llevaban de San Miguel a su trabajo observó, atónito, unas carretas haladas por caballos que surcaban penosamente un sendero cenagoso por el que también transitaban gentes extrañas vestidas extrañamente”.

(“El soñador", 29).

* La Ilogicidad: en este mundo nocturno que nos ha tocado vivir no es válido el determinismo del mundo, de los objetos, ni su lógica. Al explorar y describir esos abismos, el narrador de hoy se ve obligado a abandonar el viejo instrumental de la razón y de las ciencias naturales, tan caro al espíritu del siglo XIX, y debe "perder" los atributos de coherencia y claridad que aquella mentalidad consideraba como supremos. Aparecerá entonces la escritura automática, la asociación de imágenes, lo grotesco y esperpéntico:

"Pero ponderó Aquiles su situación y se dijo: si yo debo transitar un sinnúmero de medianías de la que está hecha cualquier distancia, la tortuga ha debido pasar por los mismos ángstrom que la separan de mí. Y entonces ella sigue en el mismo punto de partida, detenida como yo, inmóvil a mi lado y para siempre".

(“Lo que Zenón no dijo", 55).

El descubrimiento del otro: se empieza a advertir la presencia del "otro" en la medida en que el hombre parece hundirse más en sus propios abismos. Por lo que sea, nuestra época ha sido la del descubrimiento del "otro" a partir del descubrimiento del "mi mismo". Esto ha sido de gran trascendencia para el pensamiento pero de mucha más importancia para lo narrativo -la novela-, ya que su misión es "ocuparse del yo en relación con las otras conciencias que lo rodean". De este modo, frente a la subjetividad de los románticos, también de estirpe naturalista, la ficción "avanzó hacia la intersubjetividad, hacia una descripción de la realidad total desde los diferentes yoes": 
"Entran juntos al estadio, hablan del equipo -jambos apuestan sus pasiones por el mismo!- y comienza el partido. Pero usted, apabullado por esa extraña sensación de que usted está sentado al lado de usted mismo, se pierde por entero en pensamientos circulares, en sensaciones truncas, dejando de apreciar por completo que ya su equipo va ganando 3 a 0 . Mira de reojo a su amigo varias veces y otras tantas, ipero no hay vuelta que darle! Usted se reconoce a cada instante en la cara del otro". ("Que en paz descanse Antonio B...", 17).

"Encerrado en su cuarto oscuro apenas iluminado por la tenue incandescencia bermeja de la lámpara de revelado, vio como tantas veces antes aparecer gradualmente la imagen de la foto que desarrollaba. ¡Era él mismo, allí tendido en el suelo de la habitación contigua a su laboratorio, un puñal clavado en la espalda!".

("Foto velada", 40).

El mundo desde el yo: desaparece la vieja y abstracta división entre el sujeto y el objeto. Y con ella el concepto de mundo y de paisaje tal como lo concebía el narrador de antes. En la novela actual, al menos en sus manifestaciones más representativas, la escena va surgiendo desde el sujeto, junto con sus estados de alma, con sus visiones, con sus sentimientos e ideas, con sus contradicciones:

"Pero dejadme que ahora les cuente mis últimos infortunios, aquellos que han terminado por destruirme la moral y, para siempre, la autoestima. ¡Ah!, pero olvidaba deciros antes que soy también poco comunicativo y no me gusta hablar con nadie. Aunque, peor aún, soy un gran mentiroso".

(“El hombre subterráneo", 84).

"Jamás dio una opinión o emitió un juicio. Jamás dijo qué le apetecía o que le disgustaba. Jamás levantó la voz ni perjuró. Jamás orinó fuera de la taza del retrete. Jamás quemó su chaqueta con la lumbre de su cigarrillo. Jamás deseó a la mujer del prójimo. Jamás bostezó sin cubrirse con la mano ni dejó de lavarse los dientes antes de acostarse. Jamás mintió pero jamás dio su verdad”.

("El hombre enjaulado", 58). 
* El tiempo interior: al sumergirse en el yo, el escritor provoca una ruptura con el tiempo, pues el yo no está en el espacio sino "desplegado en el tiempo anímico" que corre por sus venas y no se mide en horas ni en minutos sino en esperas angustiosas, en lapsos de felicidad o de dolor en éxtasis. Este hecho no es gratuito ni bizantino, como podría inferirse de algunas críticas superficiales a la actual novelística; este hecho es consecuencia de la rigurosa necesidad de "verdad" que acosa al escritor de hoy: el hombre y solo el hombre es el centro de la creación, y el examen y descripción de su realidad no pueden ser ideados, mediante la falsificación, en un tiempo no humano. El monólogo interior que todo lo contiene será emblemático:

"Cuando nací, mi padre tenía 25 años -le dijo el hombre al afamado profesor-, es decir, 2,500 por ciento más de edad que yo. 25 años más tarde, la diferencia de edades entre ambos era solo el doble, es decir, un $100 \%$. Y ahora, 30 años más tarde, me encuentro con 55 años de edad y mi padre exactamente de 80, o sea, apenas un $31.25 \%$ de diferencia a su favor. A este ritmo, ¿cuándo lo alcanzaré?".

("Ciencias exactas", 74).

"Puesto que las coincidencias siempre existieron y han de existir hasta el final de los tiempos, esta triste coincidencia se dio así: sus primeros nueve hijos murieron todos, por coincidencia el mismo día en que cumplieron los ocho años. Por eso, y aunque nadie nunca la entendió muy bien, cuando su décimo vástago nació, creció hasta los siete años y estaba cercano a cumplir uno más, la precavida señora decía que tenía "siete añitos para nueve".

(“Siete añitos para nueve”, 77).

*

El subconsciente: en el descenso al yo el narrador no solo tiene que enfrentarse con la subjetividad a la que ya nos tenía acostumbrados el romanticismo, sino también con las "regiones profundas del subconsciente y del inconsciente". Esa sumersión en zonas tenebrosas produce muy a menudo una tonalidad nocturna y fantasmal que 
recuerda al sueño o a la pesadilla y revela la común raíz de novelas como El Proceso, de Kafka, y de cuadros como los de Van Gogh, Chirico y Roualt. En ese subsuelo no rige la ley del día y la razón sino la ley de las tinieblas:

"En un comienzo se trataba de una deformidad que no le decía nada. Pronto creyó ver el perfil de una flor brotando de un tallo. Luego la vio crecer y convertirse en una preciosa hortensia. Pero la imagen aquella se fue desfigurando y apareció, entonces, algo así como el rostro imperfecto de un hombre. Este evolucionó lenta pero nítidamente en la figura de un fauno, primero con una cara adusta y después sonriéndole desde lo alto, mostrando toda su dentadura delineada perfectamente por una boca semiabierta y burlona.

Pasaron algunas semanas y, una madrugada, se despertó traspirando luego de sentir un inexplicable ardor en todo el cuerpo y la impresión agobiante de que algo la oprimía. Se había quedado dormida bocabajo y, cuando se volteó, tuvo la angustiosa sensación de que el techo casi la aplastaba y de que el íncubo de la mancha la rozaba con sus labios lujuriosos".

(“Travesuras de un fauno", 71).

La comunión: al prescindir de un punto de vista suprahumano, al reducir la novela a un conjunto de seres que "viven la realidad desde su propia alma”, el narrador acaba por confrontarse con uno de los más profundos y angustiosos problemas del hombre: "el de su soledad y su comunicación":

"Prefirió caminar hasta su miserable pensión y, llegada la noche, se metió a la cama a hojear el periódico. Y en la página de los obituarios leyó su nombre en un recuadro publicado por la empresa, en el que su jefe lamentaba la desaparición prematura de tan apreciado servidor. Sin inmutarse pensó más bien en que los diarios, contrario a lo que repetía siempre el jefe, algunas veces sí dicen la verdad".

(“El jefe no siempre tiene la razón”, 41). 


\section{A manera de coda}

Podemos decir que la narrativa contemporánea iberoamericana no solo da cuenta de una realidad más compleja y verdadera que la del siglo XIX, sino que ha adquirido una dimensión metafísica que no tenía. La soledad, el absurdo y la muerte, la esperanza y la desesperación, son temas perennes en toda gran literatura. Pero es evidente que se ha necesitado la presencia de la crisis general de la civilización para que adquiera terrible y desnuda vigencia.

La narrativa de hoy, por ser la del hombre en crisis, es la narración de los grandes temas pascalianos. Y en consecuencia, no solo se ha lanzado a la exploración de territorios que los narradores ni siquiera sospechaban sino que, en su doble travesía, ha adquirido también una gran dignidad filosófica y cognoscitiva. Ella, la narrativa, es la actividad más compleja del espíritu de hoy, la más integral y la más promisoria en su intento de indagar y expresar, mediante la ficción de la realidad, el drama que nos cabe vivir.

La individualidad ha tocado fondo a través de la imaginación y, así, se ha cobijado en el conjuro de la palabra para convocar desde allí un mundo liberado en donde el claroscuro de lo fantástico se halla adherido en la hondura del cuerpo, en el propio "bolsillo" del hombre. 